\title{
DESAIN EKSPERIMEN UNTUK MENINGKATKAN KUALITAS KEKUATAN PRODUK DENGAN PENDEKATAN ANALISIS DESAIN FAKTORIAL
}

\author{
Ahmad $^{1)}$, Lithrone Laricha Salomon ${ }^{1)}$ dan Jessica ${ }^{2)}$ \\ ${ }^{1)}$ Staf Pengajar Program Studi Teknik Industri Universitas Tarumanagara \\ ${ }^{2)}$ Mahasiswa Program Studi Teknik Industri Universitas Tarumanagara \\ e-mail: ahmadmambas@yahoo.com,laricha_salomon@yahoo.com, jessica.tin@stu.untar.ac.id
}

\begin{abstract}
ABSTRAK
Produk webbing and elastic tape, adalah beberapa produk andalan yang di produksi oleh PT AMF. kedua produk tersebut merupakan produk setengah jadi yang akan diolah kembali oleh perusahaan lain yang membutuhkan. Pada saat kegiatan produksi berlangsung banyak permasalahan terjadi sehingga faktor yang berepengaruh terhadap kualitas tidak teridentifikasi dengan baik. Untuk itu perlu dilakukan analisis menggunakan metode six sigma dan factorial design dengan melakukan uji tarik untuk menemukan factor-faktor yang berpengaruh terhadap kualitas. Selain itu dapat diketahui settingan optimum sehingga didapatkan suatu produk terbaik. Dari analisis data, diketahui Defect per Million Opportunities pada Tahun 2016 sebesar 9295.597 dengan tingkat sigma 3.85, ini menunjukan proses kegiatan dalam keadaan baik. Perancangan desain eksperimen telah dilakukan dengan menguji 3 faktor yang dinilai berpengaruh terhadap kualitas produk, yaitu desain, kecepatan dan jenis benang. Analisis perhitungan menunjukkan bahwa semua variable input mempengaruhi variable respon. Pada main effect dan interaction plot for respon diketahui desain dan jenis benang memiliki pengaruh lebih kuat terhadap kekuatan, dibandingkan dengan kecepatan yang pengaruhnya relatif kecil. Hasil optimum di dapatkan, pada webbing tape adalah desain A2, kecepatan B1 $55 \mathrm{~cm} /$ menit, jenis benang C3 filamen. Sedangkan pada elastic tape adalah desain A3, kecepatan B3 $32 \mathrm{~cm} /$ menit, dan jenis benang C3 nilon.
\end{abstract}

Kata Kunci: DMAIC, Six sigma, Desain Faktorial, uji tarik, kualitas Produk.

\begin{abstract}
Webbing product and elastic tape are some mains product which produced by PT AMF. They are unfinished products which will be remade by the other factory which need them. There are many problems happened in the process of production, so the factors influenced the quality unidentified. To solve this problem, it is needed to analise it by using six sigma and design factorial methods. In this methods, the reseachers did the test to identify the problems and optimum setting in order to get the best product. From data analises, it is known that defect per million oppotunities is 9295.597 in 2016 with sigma level 3.85. it shows that process in running well. Design eksperimental was done by examining three factors that influenced the product quality, they are design, speed and kind of thread. From calculation analises showers that all the imput variables influence the respond variables. In the main effect and plot interaction for responds known that design and kind of thread give the stronger influenced than the speed. The optimal result got in the webbing tape is design A2, the speed B1 is $55 \mathrm{Cm} / \mathrm{minute}$, kind of thread is C3 filamen, while in the elastic tape is design A3, the speed B3 is $32 \mathrm{Cm} / \mathrm{minute}$, and kind of thread is C3 Nilon.
\end{abstract}

Keyword: DMAIC, Six Sigma, Factorial Design, Tensile test, Product Quality

\section{PENDAHULUAN}

PT. AMF, bergerak di bidang textil dan garment yang menerapkan sistem pengendalian kualitas. Produk yang utama dari perusahaan adalah webbing and elastic tape, dimana hasil produksinya merupakan kain setengah jadi (grey) yang akan diolah kembali oleh perusahaan/pabrik lainnya sebagai customer. Pada kegiatan webbing and elastic tape terdapat 3 divisi bagian, yaitu braiding, weaving and knitting. Permasalahan yang dihadapi oleh perusahaan adalah banyak terjadinya kesalahan pada kegiatan produksi yang menyebabkan cacat produk yang tidak sesuai standar. Masalah-masalah tersebut dianalisis menggunakan metode six sigma dan proses perancangan eksperimen dengan mengunakan factorial design dimana pengamatan yang dilakukan berdasarkan uji tarik sehingga dapat diketahui berbagai faktor yang memberikan kekuatan. Kekuatan produk ini menjadi indikator kualitas mutu produk webbing and 
elastic tape. Tujuan yang hendak dicapai dalam penelitian ini adalah meminimalkan faktor penyebab tingkat kecacatan dan menganalisis faktor penyebab dengan melakukan pengujian uji tarik untuk mendapatkan produk yang terbaik. Data yang di olah dalam penelitian ini adalah data historis dan hasil observasi langsung. Dalam penelitian ini analisisnya menggunakan Six sigma dan perancangan eksperimen, namun tidak memasukan faktor biaya.

\section{LANDASAN TEORI}

\section{Six Sigma}

Pengertian kualitas menurut American Society For Quality[1]: "Quality is the totality of features and characteristic of a product or service that bears on it's ability to satisfy stated or implied need." Artinya kualitas/mutu adalah keseluruhan corak dan karakteristik dari produk atau jasa yang berkemampuan untuk memenuhi kebutuhan yang tampak jelas maupun yang tersembunyi. Pengertian dari Six Sigma adalah suatu visi peningkatan kualitas menuju target 3,4 kegagalan per sejuta kesempatan untuk setiap transaksi produk barang dan jasa [2]. Jadi six sigma merupakan suatu metode atau teknik pengendalian dan peningkatan kualitas dramatic yang merupakan terobosan baru dalam bidang manajemen kualitas. Six sigma merupakan pendekatan menyeluruh untuk menyelesaikan masalah dan peningkatan proses melalui DMAIC, sedangkan DMAIC merupakan jantung analisis six sigma yang menjamin voice of customer berjalan dalam keseluruhan proses sehingga produk memuskan keinginan pelanggan [3] serta sesuai dengan prinsip six sigma yang sangat fokus pada pelanggan [4].

Tahap-tahap implementasi peningkatan kualitas dengan Six sigma terdiri dari lima langkah yaitu menggunakan metode DMAIC (Define, Measure, Analyse, Improve, and Control) [5].

a. Define

Define adalah penetapan sasaran dari aktivitas peningkatan kualitas Six Sigma. Termasuk dalam langkah definisi ini adalah menetapkan sasaran dari aktivitas peningkatan kualitas six sigma itu. Pada tingkat manajemen puncak, sasaran-sasaran yang ditetapkan akan menjadi tujuan strategi dari organisasi seperti: meningkatkan return on investement (ROI) dan pangsa pasar. Pada tahap define dapat dilakukan dengan menggunakan critical to quality, SIPOC diagram, Voice of Customer, Flowchart proses produksi, dan peta proses operasi.

b. Measurement

Dua sasaran utama pada measure yaitu mendapatkan data untuk memvalidasi dan mengkualifikasikan masalah dan peluang. Biasanya ini merupakan informasi kritis untuk memperbaiki dan melengkapi anggaran dasar proyek yang pertama dan memulai menyentuh fakta dan angka-angka yang memberikan petunjuk tentang akar masalah. Pada tahap measure dapat dilakukan dengan menggunakan $\mathrm{X}$ and $\mathrm{R}$ control chart, diagram pareto, kapabilitas proses, DPMO.

c. Analyze

Merupakan langkah operasional yang ketiga dalam program peningkatan kualitas six sigma. Ada beberapa hal yang harus dilakukan pada tahap ini, yaitu Menentukan stabilitas dan kemampuan (kapabilitas) proses, menetapkan target kinerja dari karakteristik kualitas kunci, mengidentifikasi sumber-sumber dan akar penyebab masalah kualitas. Pada analyze dapat dilakukan dengan menggunakan fishbone and Fault Tree Analyze (FTA).

d. Improve

Pada langkah ini diterapkan suatu rencana tindakan untuk melaksanakan peningkatan kualitas Six sigma. Rencana tersebut mendeskripsikan tentang alokasi sumber daya serta prioritas atau alternatif yang dilakukan. Pada improve dapat dilakukan penyelesaian masalah berupa factorial design.

\section{Perhitungan dan Pengukuran Yield dan DPMO}

Six Sigma merupakan program peningkatan kualitas yang memberikan toleransi kesalahan atau cacat. Semakin banyak cacat yang terjadi pada proses, menunjukkan semakin rendahnya pencapaian kualitas pada 
proses tersebut. Peluang-peluang kesalahan dan persentase item tanpa cacat dalam "level sigma" diberikan dalam Tabel 1. [6]

Tabel 1. Konservasi Sigma Sederhana

\begin{tabular}{ccc}
\hline $\begin{array}{c}\text { Yield }= \\
\text { persentase } \\
\text { item tanpa } \\
\text { cacat (\%) }\end{array}$ & $\begin{array}{c}\text { Defect per } \\
\text { million } \\
\text { oppurtunities } \\
\text { (DPMO) }\end{array}$ & $\begin{array}{c}\text { Level } \\
\text { sigma }\end{array}$ \\
\hline 30,9 & 690.000 & 1 \\
69,2 & 308.000 & 2 \\
93,3 & 66.800 & 3 \\
99,4 & 6.210 & 4 \\
99,98 & 320 & 5 \\
99,9997 & 3,4 & 6 \\
\hline
\end{tabular}

\section{Factorial Design}

Eksperimen yang dilakukan banyak melibatkan dua atau lebih faktor. Dengan desain faktorial, maka setiap kemungkinan level kombinasi dari semua faktor akan diselidiki. Sebagai contoh, apabila terdapat a level dari faktor A dan b level dari faktor B, maka replikasi percobaan akan dilakukan untuk setiap kombinasi ab. Efek dari suatu faktor didefinisikan sebagai respons yang dihasilkan dari perubahan level faktor tersebut. Hal ini seringkali disebut sebagai efek utama karena mengacu pada faktor primer dari percobaan. Selain efek utama, terdapat pula efek interaksi yaitu perbedaan antara efek satu faktor pada level yang berbeda dari faktor lain. Eksperimen factorial digunakan untuk menyelidiki secara bersamaan efek terhadap beberapa faktor berlainan. Factorial design digunakan untuk dampak simultan lebih dari satu variabel bebas [7].

Beberapa kelebihan dari penggunaan desain faktorial dalam perancangan suatu eksperimen selain Informasi yang diperoleh lebih komprehensif karena kita bisa mempelajari pengaruh utama dari interaksi, Hasil percobaan juga dapat diterapkan dalam suatu kondisi yang lebih luas karena kita mempelajari kombinasi dari berbagai faktor.

Desain faktorial ini pada umumnya mempunyai tiga tujuan utama yaitu:

a. Mengukur pengaruh variabel terhadap hasil

b. Menentukan variabel yang paling berpengaruh terhadap hasil c. Mengukur interaksi antar-variabel terhadap hasil Selain pengaruh faktor utama, pengaruh interaksi antar faktor terhadap hasil percobaan merupakan suatu hal yang penting untuk ditinjau. Hal ini disebabkan oleh pengaruh suatu faktor terhadap hasil bisa saja dipengaruhi oleh jumlah faktor atau ada tidaknya faktor lain.

\section{Uji Tarik}

Setiap material atau bahan memiliki sifat (kekerasan, kelenturan, kekuatan, dan sebagainya) yang berbeda-beda. Untuk mengetahui sifat dari suatu material maka diperlukan suatu pengujian. Salah satu pengujian yang paling sering dilakukan yaitu uji tarik (tensile test). Pengujian ini memiliki fungsi untuk mengetahui tingkat kekuatan suatu material dan untuk mengenali karakteristik pada material tersebut. Prinsipnya, uji tarik ini dilakukan menggunakan mesin yang dapat memberikan gaya tarik yang cukup kuat pada material dan juga memberikan cengkraman yang kencang sehingga material tidak terlepas ketika diberikan gaya tarik. Ada banyak hal yang bisa didapatkan dari uji tarik, dengan memberikan gaya tarik pada material sampai putus, maka semua susunan struktur material bisa diketahui dengan jelas sehingga dapat menentukan kualitas dari material tersebut [8].

\section{METODE PENELITIAN}

Objek penelitian ini adalah produk webbing and elastic tape. Metodologi yang digunakan dalam penelitian ini dapat dibagi menjadi empat tahap, yaitu tahap awal penelitian, tahap pengumpulan data, tahap pengolahan data dan analisis, dan kesimpulan serta saran. Data primer pada penelitian ini diperoleh melalui observasi lapangan, wawancara, serta dokumentasi dan menggunakan data sekunder yang diperoleh dari studi literature, dan sumber buku. Secara sistematis adalah sebagai berikut:

a. Tahap Awal Penelitian

Tahap awal penelitian meliputi penentuan tema dan topik penelitian, studi pustaka dan studi lapangan, penentuan identifikasi masalah, penentuan rumusan masalah, 
penentuan tujuan penelitian dan penentuan dan batasan masalah.

b. Tahap Pengumpulan Data

Tahap pengumpulan data meliputi penyusunan data umum perusahaan, pengumpulan data produksi perusahaan, pengumpulan informasi data perusahaan, dan perancangan eksperimen.

c. Tahap Pengolahan data dan Analisis

Tahap pengolahan data dan analisis meliputi penentuan faktor-faktor terkontrol dan level, analisis DMAIC, dan factorial Design.

d. Kesimpulan

Langkah-langkah dalam pengujian webbing and elastic tape yaitu mengambil sampel produk webbing and elastic tape. Setiap Sampel yang diambil panjang $30 \mathrm{~cm}$, produk yang akan diuji ditandai sebagai identitas produk. Kemudian melakukan pengukuran 13 cm dari atas serta bawah sehingga menyisakan $4 \mathrm{~cm}$ sebagai acuan daerah tarik, memulai pengujian dengan memasukkan produk webbing/elastic pada ragum di mesin uji tarik, kencangkan kunci ragum dengan palu agar spesimen tidak terlepas, atur garis penunjuk dengan dimulai dari angka 0 , kemudian atur skala beban pada satu garis sebesar $10 \mathrm{kgf}$, dan nyalakan mesin serta melihat perubahan pada tape hingga mencapai titik maksimal/titik patah.

\section{Define \\ HASIL DAN PEMBAHASAN}

a. Diagram SIPOC

Diagram SIPOC memberikan gambaran yang jelas mengenai pengaruh dari proses terhadap pelayanan konsumen, membantu dalam menjelaskan suatu proyek yang kompleks, namun ruang lingkupnya kurang jelas. Dalam praktik di lapangan, SIPOC dapat dianggap sebagai high-level process map karena sering digunakan saat menentukan fase dari suatu process improvement project yaitu lebih memfokuskan pada identifikasi VOC (Voice of Customer). Berikut penjelasan mengenai diagram SIPOC yang terjadi pada PT. AMF dalam memproduksi webbing and elastic tape dapat dilihat pada Gambar 1.

\section{b. Voice of Customer}

Perusahaan ini berusaha memenuhi kebutuhan pelanggannya sesuai dengan kebutuhan customernya. Oleh sebab itu, dengan sistem custom to order ataupun make to order,

\section{DIAGRAM SIPOC \\ Supplier-Input-Process-Output-Costumer}

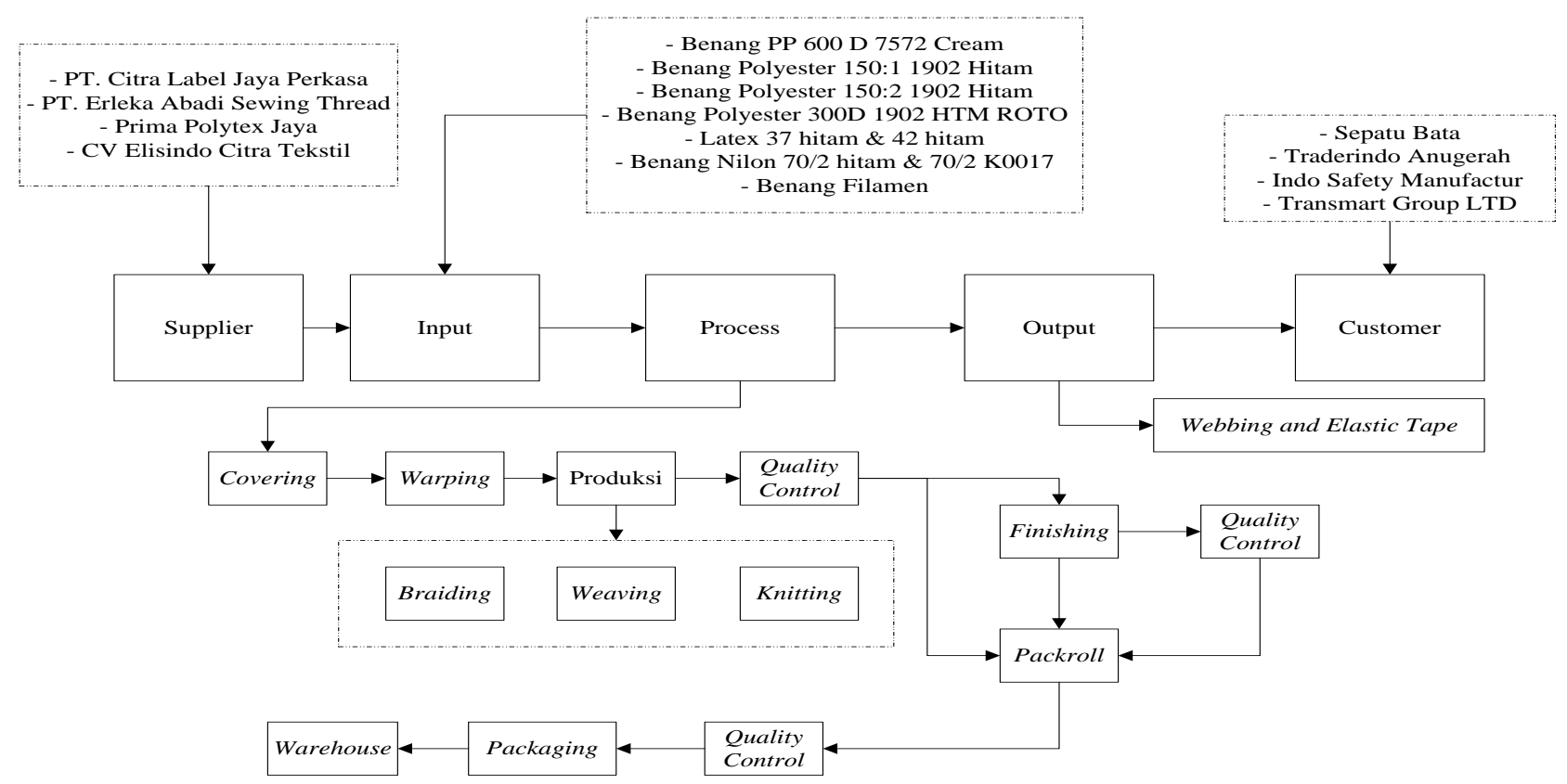

Gambar 1. Diagram SIPOC 
Tabel 2. Contoh Voice of Customer pada Produk POLO

\begin{tabular}{ccc}
$\begin{array}{c}\text { Voice of The Customer } \\
\text { What the customer wants. }\end{array}$ & $\begin{array}{c}\text { CTQ Description } \\
\text { How we will deliver what the } \\
\text { customer wants }\end{array}$ & $\begin{array}{c}\text { CTQ Measurement } \\
\text { How we will measure what we } \\
\text { deliver }\end{array}$ \\
\hline & Benang disesuaikan dengan & Filamen $: \geq 400 \mathrm{~kg}$ \\
penggunaan customer & PP $: 150-400 \mathrm{Kg}$ \\
& & Polyester $: \leq 100 \mathrm{Kg}$ \\
& Benang supplier dicek & Benang Luar : 48H PP600 \\
& kualitas & Benang Luar III: 40 H PP 600 \\
\hline
\end{tabular}

salah satu strategi dalam memenuhi permintaan customer adalah dengan mengaplikasikan voice of customer dengan cara mengirimkan sampel terlebih dahulu terhadap customer hingga customer menyetujui sampel yang diberikan. Berikut merupakan voice of customer pada produk POLO dapat dilihat pada Tabel 2.

Desain pola produk webbing dan elastic tape pada perusahaan PT. AMF dirancang berdasarkan kebutuhan konsumen dan spesifikasi dari perusahaan. Pola desain webbing dan elastic tape dapat dilihat pada Gambar 2 dan Gambar 3.

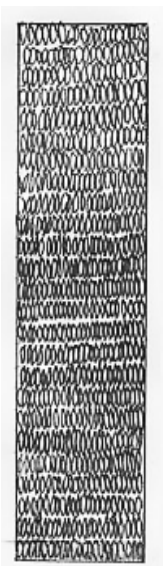

DESAINAI

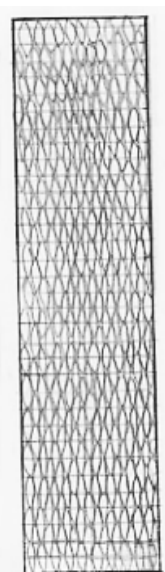

DESAIN A?

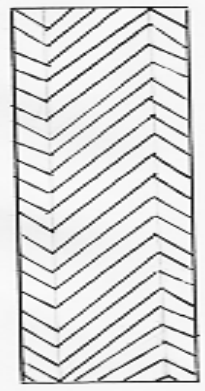

DESAINA3
Gambar 2. Desain/pola webbing
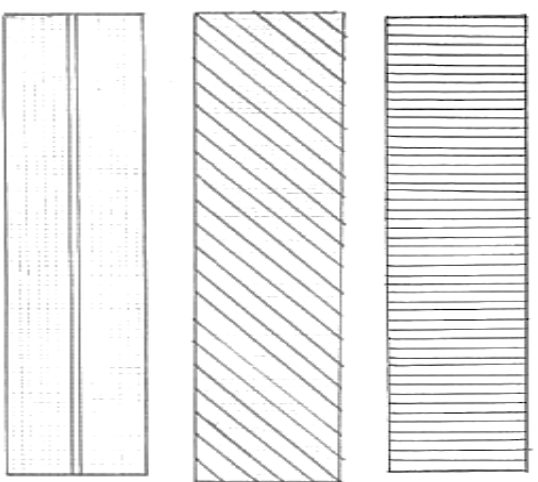

Gambar 3. Desain produk Elastic Tape

\section{c. Critical To Quality}

Aktivitas utama selanjutnya dalam tahap define adalah menentukan CTQ (Critical to Quality), yaitu merupakan fokus permasalahan yang paling penting untuk memenuhi keinginan customer. Critical To Quality (CTQ) merupakan karakteristik dari sebuah produk atau jasa yang memenuhi kebutuhan konsumen. CTQ tree produk webbing dapat dilihat pada Gambar 4.

\section{Measurement}

Pada tahap kedua dalam DMAIC adalah measurement (tahap pengukuran). Tahap ini dilakukan untuk mengukur performansi proses sebelum dilakukan perbaikan.

a. Control Chart $X$ and $R$

Sebelum dilakukan penelitian, dilakukan evaluasi dan perlunya memahami kondisi proses produksi yang terdapat di PT. AMF dengan cara menggunakan peta kendali Xbar yang bertujuan untuk menjelaskan mengenai perubahan-perubahan yang telah terjadi dalam ukuran titik pusat atau ratarata dari proses, sedangkan peta kontrol $\mathrm{R}$ menjelaskan tentang apakah perubahanperubahan telah terjadi dalam ukuran variasi atau perubahan homogenitas produk yang dihasilkan dalam ukuran variasi. Data yang digunakan merupakan data historis Tahun 2016. Berikut merupakan tabel Control Limit For $X$ chart and For The $R$ Chart Tahun 2016 yang dapat dilihat pada Tabel 3 dan Gambar control chart Tahun 2016 dapat dilihat pada Gambar 5. 


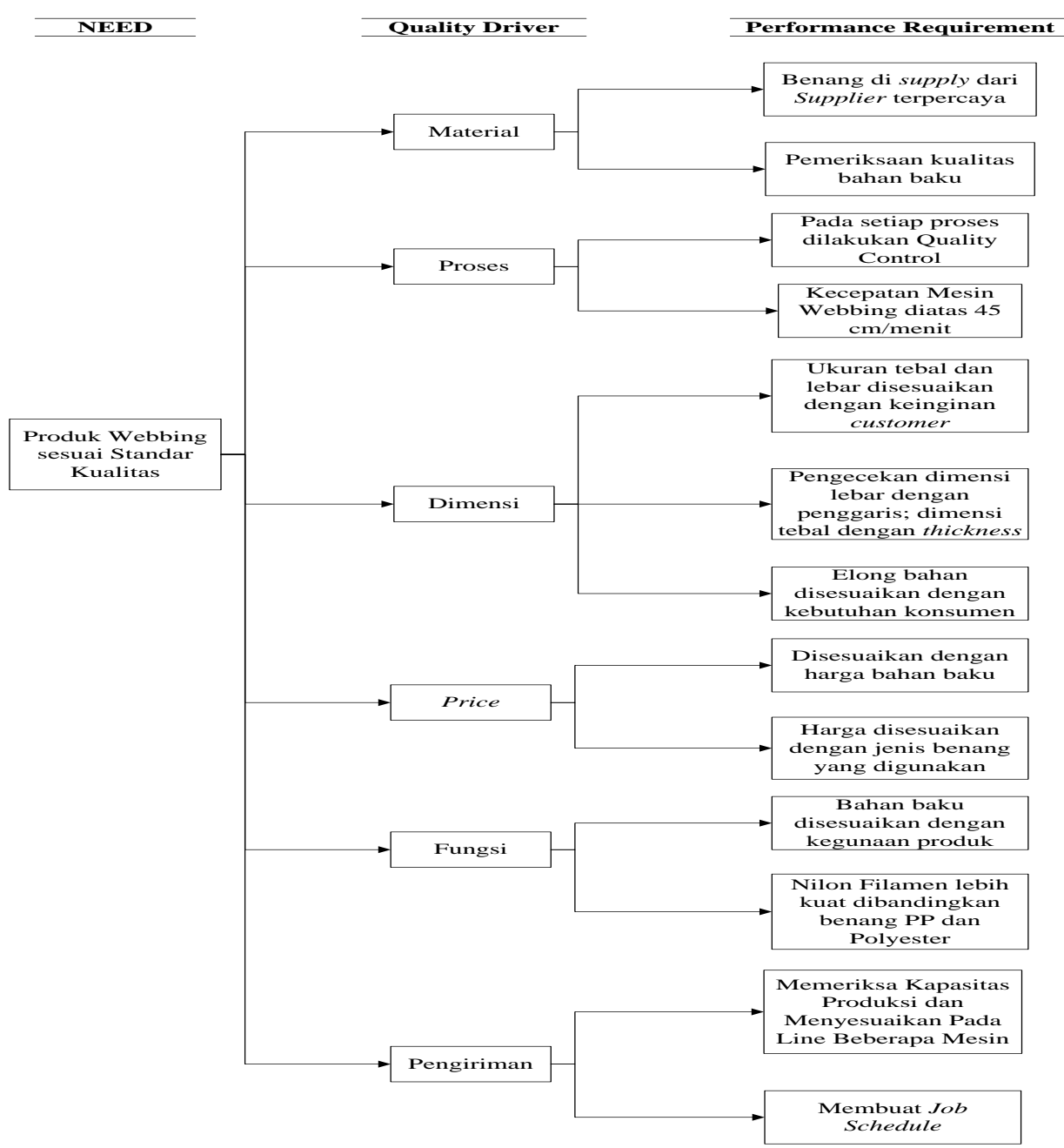

Gambar 4. CTQ Tree Produk Webbing

Tabel 3. Control Limit For X chart and For The R Chart Tahun 2016

\begin{tabular}{cccc}
\hline CONTROL LIMIT FOR THE $\boldsymbol{X}$ CHART & CONTROL LIMIT FOR THE R CHART \\
\hline A2 $=0.729$ & D3 $=0$ & \multicolumn{2}{c}{ D4=2.282 } \\
\hline CL & 244.6 & CL & 209.8 \\
\hline UCL & 397.4 & UCL & 478.6 \\
\hline LCL & 91.8 & LCL & 0
\end{tabular}

b. DPMO (Defect Per Million Opportunities) Perhitungan DPMO dan level sigma bermaksud mengukur kemampuan dan kapabilitas sigma pada saat ini. Perhitungan DPMO dilakukan pada Tahun 2016. Adapun nilai-nilai yang diperlukan untuk menghitung nilai DPMO dalam bentuk variable dalam satuan dengan Opportunity menyatakan karakteristik yang berpotensi menyebabkan cacat yaitu sebanyak dua defect, yaitu defect steel dan defect produksi. Tabel DPMO Tahun 2016 dapat dilihat pada Tabel 4. c. Diagram Pareto

Diagram pareto digunakan untuk mengidentifikasi permasalahan yang lebih utama sehingga dapat dilakukan analisis dan perbaikan mendalam terhadap defect. Dengan total defect pada Tahun 2016 sebesar 11,739.79 kg dengan presentase defect stell sebesar $26.023 \%$ dan defect produksi sebesar $73.977 \%$ menunjukkan bahwa defect produksi memerlukan perhatian yang lebih khusus agar dapat lebih optimal dengan beberapa langkah perbaikan. 

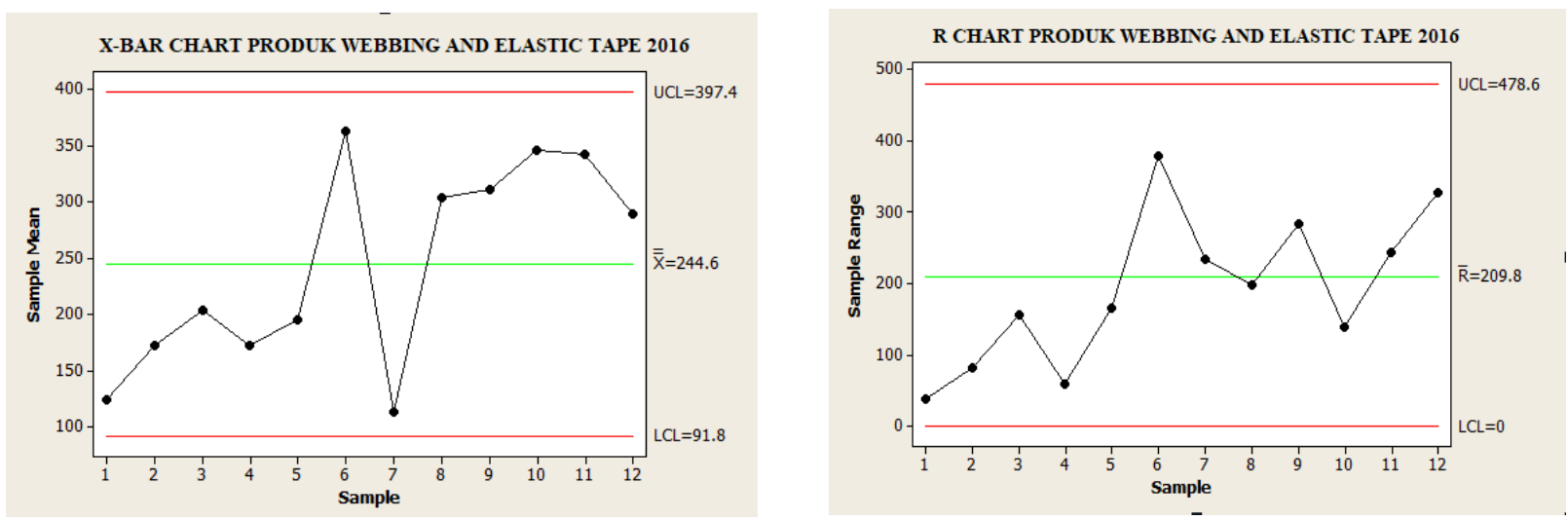

Gambar 5. Control Limit For X chart and For The R Chart Tahun 2016

Berikut diagram pareto dapat dilihat pada Gambar 6.

Tabel 4. DPMO Tahun 2016

\begin{tabular}{ll}
\hline \multicolumn{2}{c}{ KETERANGAN 2016} \\
\hline Unit (Kg) & $631,470.45$ \\
\hline Opportunities & 2 \\
\hline Defect (Kg) & $11,739.790$ \\
\hline Defect per unit & 0.018591195 \\
\hline Total Opportunities & 1262940,9 \\
\hline Defect per opportunities & 0,009295597 \\
\hline DPMO & 9295,597 \\
\hline Tingkat sigma & 3,85 \\
\hline
\end{tabular}

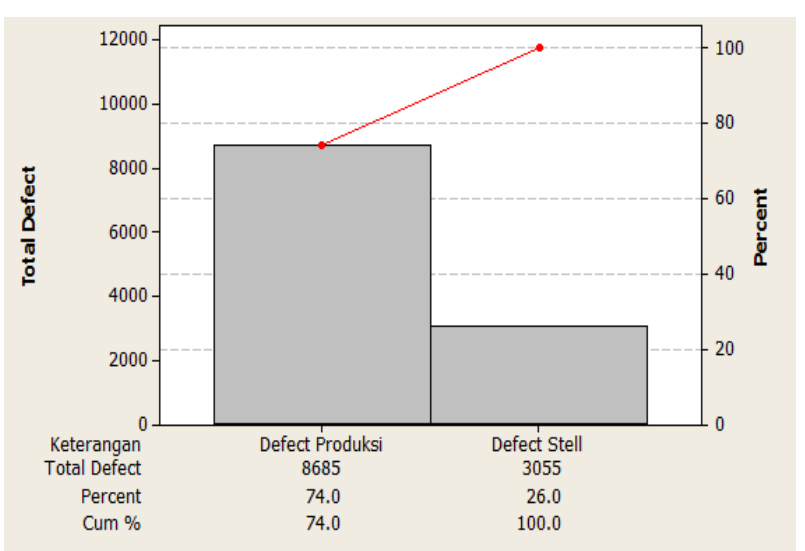

Gambar 6. Diagram Pareto Tahun 2016

\section{Analyze}

Dalam tahap ketiga dalam DMAIC adalah menganalisis suatu masalah dan proses. Pada tahap analyze mewujudkan target dari program six sigma, yaitu membawa proses industry pada kondisi yang memiliki stabilitas dan kemampuan sehingga mencapai tingkat kegagalan nol (zero defect oriented). Dalam proses produksi webbing and elastic tape perlu diketahui setiap factor yang memberikan permasalahan serta dibuatkan suatu solusi terhadap faktor yang dapat diminimalkan. Salah satu alat (tool) untuk menganalisis setiap permasalahan yang terjadi dapat menggunakan fishbone, and Fault the Analyze (FTA). Berikut merupakan salah satu contoh fishbone dan fault tree analyze yang disebabkan karena proses produksi, antara lain

a. Diagram Sebab Akibat

Terdapat perbedaan pada fishbone yang disebabkan karena proses stell dan proses produksi. Perbedaan yang mendasar adalah lebih banyak dalam kesalahan penanganan pada proses penyetelan atau perumusan pada mesin sehingga menghasilkan produk yang tidak standar, sedangkan pada proses produksi lebih dikarenakan benang/karet putus saat mesin sedang beroperasi sehingga tentu kesalahan cacat saat produksi jauh lebih besar dari kesalahan cacat saat produksi. Pada cacat karena produksi disebabkan oleh berbagai faktor, yaitu manusia, mesin, metode, material, dan lingkungan. Faktor manusia yang menyebabkan cacat produksi adalah kurangnya softskill yang dimiliki pekerja yang dipengaruhi oleh latarbelakang pendidikan, minimnya pengetahuan, kurangnya pelatihan serta kurang cekatan dalam mengawasi jalannya operasi dan faktor manusia lainnya adalah human error yang dapat disebabkan oleh faktor kelelahan, kurang konsentrasi, dan kurang 
teliti. Selain itu, material benang yang kurang dapat menyebabkan terjadinya defect, seperti benang mudah putus dan benang semakin tipis serta pemasangan benang yang terlalu kencang dapat menyebabkan produk rusak. Selain itu, macet dan rusaknya mesin dapat menyebabkan produk menjadi rusak Hal ini disebabkan oleh kurangnya maintenance dan pergantian sparepart pada mesin knitting, salah pemasangan benang pada jarum dan kurangnya perhatian pekerja terhadap kondisi jarum. Metode yang mempengaruhi defect dapat disebabkan oleh salahnya teknik pemasangan, tidak maksimalnya teknik pengecekkan karena adanya faktor ketidaktelitian dan terburuburu serta teknik perumusan yang tidak sesuai dengan Technical Card (TC). Lingkungan yang tidak kondusif seperti bising, suhu lembab dan cahaya yang kurang cukup juga dapat mengganggu konsentrasi pekerja sehingga ketelitian saat sedang melakukan kegiatan produksi menjadi berkurang.

b. Fault Tree Analysis

Fault tree analysis pada PT.AMF dapat disebabkan oleh beberapa faktor, yaitu faktor metode, manusia, lingkungan, material, dan mesin. Gambar fault tree analysis dapat dilihat pada Gambar 7.

\section{Improve}

Dengan menggunakan taraf signifikansi $\alpha$ $=10 \%$, maka untuk mengetahui apakah interaksi atau tidak pada variable input terhadap variable respon dapat dilakukan dengan menggunakan desain eksperimen $3^{3}$ (3 level dan 3 faktor). Data kekuatan tarik webbing tape (satuan =kgf) dapat dilihat pada Tabel 5 .

\section{Uji Hipotesa:}

\section{Hipotesa awal $\left(\mathbf{H}_{\mathbf{0}}\right)$}

$\mathrm{H}_{01}=$ Tidak adanya pengaruh antara Desain dengan kekuatan bahan

$\mathrm{H}_{02}=$ Tidak adanya pengaruh antara Kecepatan dengan kekuatan bahan

$\mathrm{H}_{03}=$ Tidak adanya pengaruh antara Jenis benang dengan kekuatan bahan

$\mathrm{H}_{04}=$ Tidak adanya interaksi antara desain dan kecepatan dengan kekuatan bahan

$\mathrm{H}_{05}=$ Tidak adanya interaksi antara desain dan jenis benang dengan kekuatan bahan

$\mathrm{H}_{06}=$ Tidak adanya interaksi antara kecepatan dan jenis benang dengan kekuatan bahan

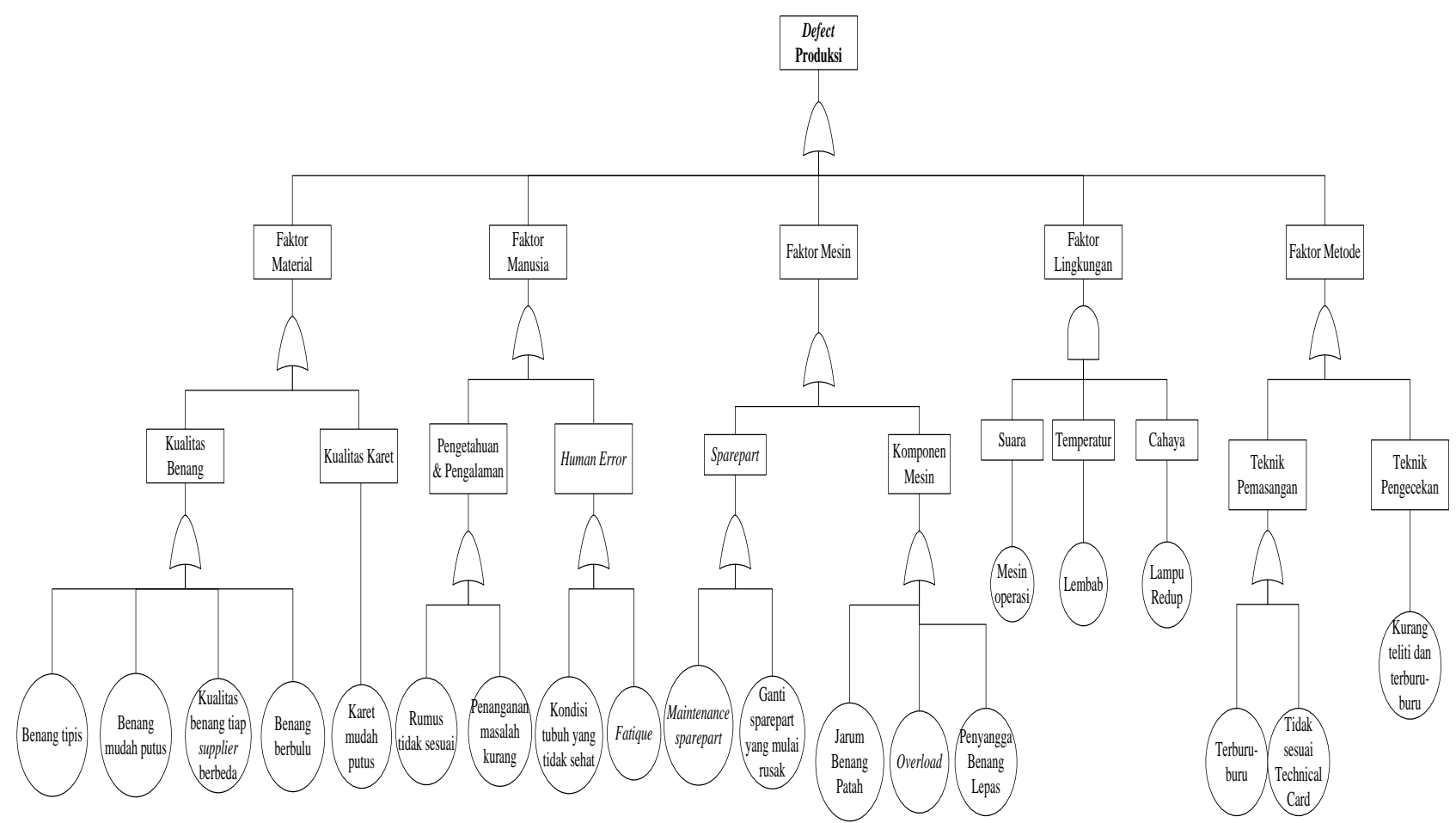

Gambar 7. Fault Tree Analysis untuk Menganalisis Defect Produksi 
Tabel 5. Data Kekuatan Tarik Webbing Tape

\begin{tabular}{|c|c|c|c|c|c|c|c|c|c|c|c|c|c|c|c|c|c|c|c|}
\hline \multirow{5}{*}{$\begin{array}{c}\text { Kualitas } \\
\text { Benang } \\
\text { [C] }\end{array}$} & \multicolumn{18}{|c|}{ Design (A) } & \multirow{5}{*}{ Yi... } \\
\hline & \multicolumn{6}{|c|}{ A1 } & \multicolumn{6}{|c|}{ A2 } & \multicolumn{6}{|c|}{ A3 } & \\
\hline & \multicolumn{18}{|c|}{ Kecepatan (B) } & \\
\hline & \multirow{2}{*}{\multicolumn{2}{|c|}{$\begin{array}{c}\text { B1 } \\
55 \\
\mathrm{~cm} / \text { menit } \\
\end{array}$}} & \multirow{2}{*}{\multicolumn{2}{|c|}{$\begin{array}{c}\text { B2 } \\
65 \\
\mathrm{~cm} / \text { menit } \\
\end{array}$}} & \multirow{2}{*}{\multicolumn{2}{|c|}{$\begin{array}{c}\text { B3 } \\
75 \\
\mathrm{~cm} / \text { menit } \\
\end{array}$}} & \multirow{2}{*}{\multicolumn{2}{|c|}{$\begin{array}{c}\text { B1 } \\
55 \\
\mathrm{~cm} / \text { menit } \\
\end{array}$}} & \multirow{2}{*}{\multicolumn{2}{|c|}{$\begin{array}{c}\mathrm{B} 2 \\
65 \\
\mathrm{~cm} / \text { menit } \\
\end{array}$}} & \multirow{2}{*}{\multicolumn{2}{|c|}{$\begin{array}{c}\text { B3 } \\
75 \\
\mathrm{~cm} / \text { menit } \\
\end{array}$}} & \multirow{2}{*}{\multicolumn{2}{|c|}{$\begin{array}{c}\text { B1 } \\
55 \\
\mathrm{~cm} / \text { menit } \\
\end{array}$}} & \multirow{2}{*}{\multicolumn{2}{|c|}{$\begin{array}{c}\mathrm{B} 2 \\
65 \\
\mathrm{~cm} / \text { menit } \\
\end{array}$}} & \multirow{2}{*}{\multicolumn{2}{|c|}{$\begin{array}{c}\text { B3 } \\
75 \\
\mathrm{~cm} / \text { menit } \\
\end{array}$}} & \\
\hline & & & & & & & & & & & & & & & & & & & \\
\hline \multirow{2}{*}{$\begin{array}{c}\text { C1 } \\
\text { (Polyester } \\
\text { 150:2 D) }\end{array}$} & 570 & \multirow{2}{*}{1140} & 585 & \multirow{2}{*}{1170} & 580 & \multirow{2}{*}{1160} & 270 & \multirow{2}{*}{540} & 285 & \multirow{2}{*}{565} & 280 & \multirow{2}{*}{560} & 350 & \multirow{2}{*}{700} & 370 & \multirow{2}{*}{740} & 365 & \multirow{2}{*}{725} & \multirow{2}{*}{7300} \\
\hline & 570 & & 585 & & 580 & & 270 & & 280 & & 280 & & 350 & & 370 & & 360 & & \\
\hline \multirow{2}{*}{$\begin{array}{c}\text { C2 } \\
\text { (PP 600 } \\
\text { D) }\end{array}$} & 460 & \multirow{2}{*}{920} & 470 & \multirow{2}{*}{945} & 455 & \multirow{2}{*}{915} & 230 & \multirow{2}{*}{460} & 230 & (C) & 250 & & 390 & & 380 & & 385 & & \\
\hline & 460 & & 475 & & 460 & & 230 & & 235 & 405 & 250 & 500 & 390 & 780 & 380 & 760 & 380 & 765 & 6480 \\
\hline $\begin{array}{c}\text { C3 } \\
\text { (Benang }\end{array}$ & 545 & 1085 & 565 & 1130 & 530 & 1060 & 750 & 1500 & 730 & 1460 & 740 & 1480 & 490 & 980 & 480 & 960 & 480 & 960 & 10615 \\
\hline Filamen) & 540 & & 565 & & 530 & & 750 & & 730 & & 740 & & 490 & & 480 & & 480 & & \\
\hline $\begin{array}{c}\text { A X B } \\
\text { Total y.ij. }\end{array}$ & & 3145 & & 3245 & & 3105 & & 2500 & & 2490 & & 2540 & & 2460 & & 2460 & & 2450 & Y...= \\
\hline y.j.. & & & & & & & & & & 30 & & & & & & & & & \\
\hline y..k. & & & & & & & & & & 95 & & & & & & & & & \\
\hline
\end{tabular}

Tabel 6. Hasil uji ANOVA Webbing Tape

\begin{tabular}{|c|c|c|c|c|c|c|}
\hline Source & $D f$ & Seq SS & Adj SS & Adj Ms & $F$ & $P$ \\
\hline Desain & 2 & 155601 & 155601 & 77800 & 24007,00 & 0,000 \\
\hline Kecepatan & 2 & 337 & 337 & 169 & 52,00 & 0,000 \\
\hline Jenis benang & 2 & 532590 & 532590 & 266295 & 82171 & 0,000 \\
\hline Desain*kecepatan & 4 & 1641 & 1641 & 410 & 126,57 & 0,000 \\
\hline Desain*jenis benang & 4 & 500430 & 500430 & 125107 & 38604,57 & 0,000 \\
\hline Kecepatan*jenis benang & 4 & 869 & 869 & 217 & 67 & 0,000 \\
\hline Desain*kecepatan*jenis benang & 8 & 1254 & 1254 & 157 & 48,36 & 0,000 \\
\hline Error & 27 & 88 & 88 & 3 & & \\
\hline Total & 53 & 1192808 & & & & \\
\hline$S=1,80021$ & $\mathrm{R}-\mathrm{Sq}$ & $=99,99 \%$ & R-Sq( & )$=99,99$ & & \\
\hline
\end{tabular}

$\mathrm{H}_{07}=$ Tidak adanya interaksi antara desain, kecepatan, \& jenis benang dengan kekuatan bahan

\section{Hipotesa Alternatif $\left(\mathbf{H}_{1}\right)$}

$\mathrm{H}_{11}=$ Terdapat pengaruh antara desain dengan kekuatan bahan

$\mathrm{H}_{12}=$ Terdapat pengaruh antara kecepatan dengan kekuatan bahan

$\mathrm{H}_{13}=$ Terdapat pengaruh antara jenis benang dengan kekuatan bahan

$\mathrm{H}_{14}=$ Terdapat pengaruh interaksi antara desain dan kecepatan dengan kekuatan bahan

$\mathrm{H}_{15}=$ Terdapat pengaruh interaksi antara desain dan jenis benang dengan kekuatan bahan

$\mathrm{H}_{16}=$ Terdapat pengaruh antara kecepatan dan jenis benang dengan kekuatan bahan
$\mathrm{H}_{17}=$ Terdapat pengaruh antara desain, kecepatan dan jenis benang dengan kekuatan bahan
Dengan bantuan software statistik, hasil pengolahan data dapat dilihat pada Tabel 6 . Dari hasil uji ANOVA pada Tabel 6, dengan taraf $\alpha=0,1$ dapat dilihat bahwa p-value yang diperoleh sangat kecil untuk setiap faktor yang diteliti sehingga diperoleh kesimpulan untuk menolak $\mathrm{H}_{0}$ Dan menerima $\mathrm{H} 1$ yang menunjukan bahwa semua faktor terkendali beserta interaksinya memberi pengaruh signifikan terhadap hasil proses.

Dari analisis lebih lanjut dengan Normal probability plot dimana plot dibentuk antara nilai data dengan nilai harapan dari data tersebut sehingga menunjukkan apakah sebaran data berdistribusi normal atau tidak. Dari Gambar 8 distribusi normal terlihat bahwa 
terdapat titik-titik disekitar garis yang menunjukkan nilai efek perlakuan.

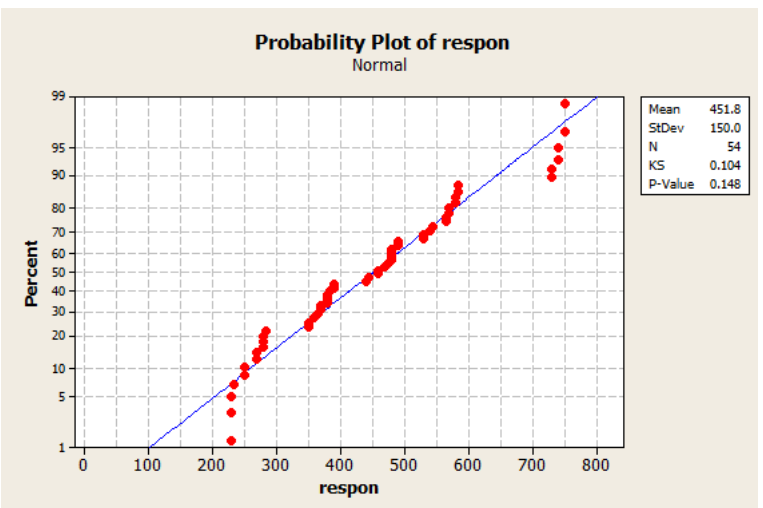

Gambar 8. Pengujian Normality Test Webbing Tape

Untuk Kondisi webbing tape dengan variable input yaitu desain, kecepatan dan jenis benang terhadap kekuatan tarik dapat dijelaskan pada main effects plot for response dan Interaction plot for response menunjukkan bahwa perubahan kecepatan tidak terlalu berarti pada kekuatan tarik dibandingkan dengan desain dan jenis benang tersebut. Hal tersebut dapat dijelaskan bahwa pada main effect plot pada kecepatan hanya mengalami perubahan yang relatif kecil dan tidak ekstrim dimana hanya mengalami kenaikan $\pm 5 \%$ serta pada interaction plot faktor kecepatan berada agak menjauhi titik faktor desain dan jenis benang. Sedangkan main effects and interaction plot for respon (webbing tape) dapat dilihat pada Gambar 9.
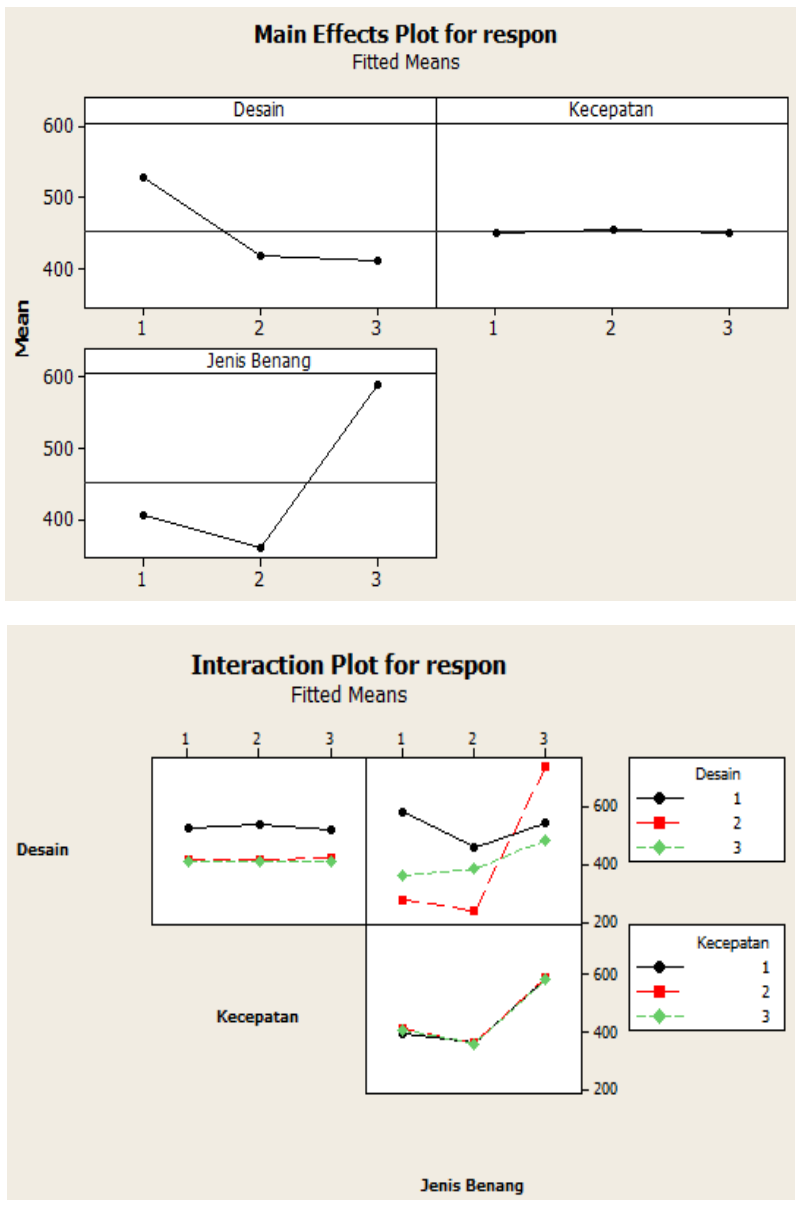

Gambar 9. Main Effects and Interaction Plot for Respon untuk Webbing Tape

Hasil uji ANOVA produk Elastic tape dapat dilihat pada Tabel 8, berdasarkan data kekuatan uji tarik pada Tabel 7.

Tabel 7. Data Kekuatan Tarik Elastic Tape

\begin{tabular}{|c|c|c|c|c|c|c|c|c|c|}
\hline \multirow{5}{*}{$\begin{array}{c}\text { Kualitas } \\
\text { Benang } \\
\text { [C] }\end{array}$} & \multicolumn{9}{|c|}{ Design (A) } \\
\hline & \multicolumn{3}{|c|}{ A1 } & \multicolumn{3}{|c|}{ A2 } & \multicolumn{3}{|c|}{ A3 } \\
\hline & \multicolumn{9}{|c|}{ Kecepatan (B) } \\
\hline & B1 & B2 & B3 & B1 & B2 & B3 & B1 & B2 & B3 \\
\hline & $\begin{array}{c}26 \\
\mathrm{~cm} / \mathrm{menit}\end{array}$ & $\begin{array}{c}29 \\
\mathrm{~cm} / \text { menit }\end{array}$ & $\begin{array}{c}32 \\
\mathrm{~cm} / \mathrm{menit}\end{array}$ & $\begin{array}{c}26 \\
\mathrm{~cm} / \text { menit }\end{array}$ & $\begin{array}{c}29 \\
\mathrm{~cm} / \text { menit }\end{array}$ & $\begin{array}{c}32 \\
\mathrm{~cm} / \mathrm{menit}\end{array}$ & $\begin{array}{c}26 \\
\mathrm{~cm} / \text { menit }\end{array}$ & $\begin{array}{c}29 \\
\mathrm{~cm} / \mathrm{menit}\end{array}$ & $\begin{array}{c}32 \\
\mathrm{~cm} / \text { menit }\end{array}$ \\
\hline \multirow{2}{*}{$\begin{array}{c}\text { C1 } \\
\text { (Polyester } \\
300 \text { D) }\end{array}$} & 45 & 35 & 45 & 65 & 60 & 65 & 60 & 60 & 55 \\
\hline & 45 & 35 & 55 & 65 & 65 & 65 & 60 & 60 & 55 \\
\hline \multirow{2}{*}{$\begin{array}{c}\text { C2 } \\
\text { (Polyester } \\
150 \text { D) } \\
\end{array}$} & 30 & 25 & 35 & 45 & 50 & 50 & 45 & 50 & 48 \\
\hline & 30 & 30 & 30 & 45 & 50 & 50 & 45 & 50 & 50 \\
\hline \multirow{2}{*}{$\begin{array}{c}\text { C3 } \\
\text { (Nilon) }\end{array}$} & 35 & 40 & 40 & 50 & 55 & 60 & 75 & 70 & 80 \\
\hline & 35 & 35 & 40 & 50 & 55 & 60 & 75 & 70 & 80 \\
\hline
\end{tabular}


Tabel 8. Hasil Uji ANOVA Elastic tape

\begin{tabular}{lcccccc}
\hline \multicolumn{1}{c}{ Source } & $D f$ & Seq SS & Adj SS & Adj Ms & $F$ & $P$ \\
\hline Desain & 2 & 5581,81 & 5581,81 & 2790,91 & 738,77 & 0,000 \\
Kecepatan & 2 & 159,59 & 159,59 & 79,80 & 21,12 & 0,000 \\
Jenis benang & 2 & 2171,81 & 2171,81 & 1085,91 & 287,45 & 0,000 \\
Desain*kecepatan & 4 & 91,96 & 91,96 & 22,99 & 6,09 & 0,001 \\
Desain*jenis benang & 4 & 1349,74 & 1349,74 & 337,44 & 89,32 & 0,000 \\
Kecepatan*jenis benang & 4 & 113,63 & 113,63 & 28,41 & 7,52 & 0,000 \\
Desain*kecepatan*jenis benang & 8 & 221,15 & 221,15 & 27,64 & 7,32 & 0,000 \\
Error & 27 & 102,00 & 102,00 & 3,78 & & \\
Total & 53 & 9791,70 & & & & \\
\hline
\end{tabular}

Dari hasil uji ANOVA pada Tabel 8, dengan taraf $\alpha=0,1$ dapat dilihat bahwa pvalue yang diperoleh juga sangat kecil untuk setiap faktor yang diteliti sehingga diperoleh kesimpulan untuk menolak H0 Dan menerima H1 yang menunjukan bahwa semua faktor terkendali beserta interaksinya memberi pengaruh signifikan terhadap hasil proses.
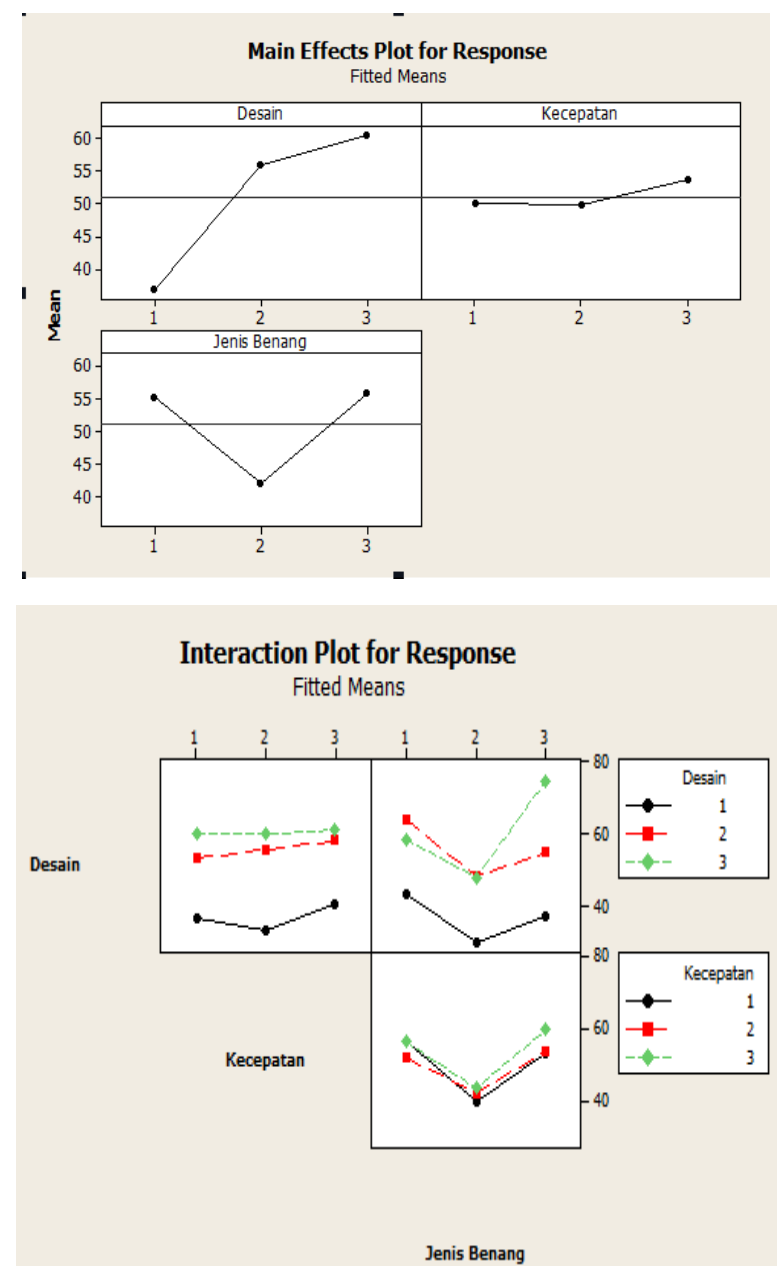

Gambar 10. Main Effect Plot For Response dan Interaction Plot For Response Elastic Tape
Kondisi pada elastic tape dengan variable input yaitu desain, kecepatan dan jenis benang terhadap kekuatan tarik dapat dijelaskan pada main effects plot for response dan Interaction plot dimana dapat dilihat pada Gambar 10 menunjukkan bahwa perubahan kecepatan tidak terlalu berarti pada kekuatan tarik dibandingkan dengan desain dan jenis benang tersebut. Hal tersebut dapat dijelaskan bahwa pada main effect plot pada kecepatan hanya mengalami perubahan yang relative kecil dan tidak ekstrem dimana hanya mengalami kenaikan $\pm 5 \%$ serta pada interaction plot faktor kecepatan berada agak menjauhi titik faktor desain dan jenis benang.

\section{KESIMPULAN}

Perancangan eksperimen menggunakan variable input dan variable respon. Variabel input pada penelitian ini adalah desain, kecepatan dan jenis benang, sedangkan pada variable respon yang digunakan adalah besarnya kekuatan tarik (dalam satuan kilogramforce). Dalam menggunakan variable input disesuaikan dengan jenis bahan produk tersebut. Pada bagian webbing mengamati kualitas benang (Benang PP $600 \mathrm{D}$, Benang Polyester 150:2 D, Benang Filamen), Speed (55 $\mathrm{cm} /$ menit; $65 \mathrm{~cm} /$ menit; $75 \mathrm{~cm} /$ menit) dan Desain $(A 1, A 2, A 3)$. Dengan menggunakan taraf signifikansi $\alpha=10 \%$, karena pada proses pengambilan data memerlukan ketelitian dan pengamatan yang tinggi. Pada analisis variable input yang mempengaruhi variable respons dengan menggunakan factorial design menunjukkan bahwa menolak $\mathrm{H}_{0}$ serta menerima $\mathrm{H}_{1}$, ini menunjukan bahwa setiap faktor maupun interaksinya saling berpengaruh. 
Setting optimum pada webbing tape adalah jenis benang C3 filamen, kecepatan $55 \mathrm{~cm} /$ menit dan desain A2. Setting optimum pada elastic tape, yaitu desain $\mathrm{A} 3$, kecepatan $32 \mathrm{~cm} /$ menit dan jenis benang C3 nilon. Pada main effect plot for response dan interaction plot for respon dapat dijelaskan bahwa desain dan jenis benang memiliki pengaruh yang lebih kuat terhadap kekuatan tarik diibandingkan dengan kecepatan yang memberikan pengaruh relative sangat kecil terhadap kekuatan tarik.

\section{DAFTAR PUSTAKA}

[1] Heizer, Jay and Barry Bender. 2006. Operations Management (Manajemen Operasi) Jakarta: Salemba Empat

[2] Gasperz, Vincent. 2005. Total Quality Management. Jakarta: PT. Gramedia Pustaka Utama.

[3] Jap, Lilyana. Lithrone Laricha S., dan Wilson Kosasih. Jurnal: Peningkatan Kualitas Benang DTY Single 150D/48F pada Mesin Cone Wender Menggunakan Metode Six Sigma dan Factorial Design di PT. Gemilang Texindotama. Program Studi Teknik Industri Universitas Tarumanagara: Jakarta.
[4] Latief, Y. \& R.P Utami. 2009. Jurnal: Penerapan Pendekatan Metode Six Sigma Dalam Penjagaan Kualitas Pada Proyek Konstruksi. Makara Teknologi. Volume 13 No 2 Hal 67-72. Universitas Indonesia. Depok

[5] Pete \& Holpp. 2002. What Is Six Sigma. Yogjakarta: ANDI.

[6] Revathi A, Sriram S. 2016. Jurnal: Implementation of Six sigma Concepts in Construction Project For Ensuring Quality Improvement. International Journal of Innovative Research in Science, Enginerring and Technology (Vol.5)

[7] Montgomery, Douglas C. 2005. Design and Analysis Of Experiments, $6^{\text {th }}$ Edition. New York.

[8] Wiryosumarto, H dan Okumura,T. 2000. Teknik Pengelasan Logam. Cetakan ke 8. Pradnya Paramita: Jakarta. 